\title{
Preparation of Hydrogel Based on Acryl Amide and Investigation of Different Factors Affecting Rate and Amount of Absorbed Water
}

\author{
Mostafa A. Radwan, Omar H. Al-Sweasy, Hany A. Elazab* \\ Chemical Engineering Department, The British University in Egypt, BUE, Cairo, Egypt \\ Email:*elazabha@vcu.edu
}

How to cite this paper: Radwan, M.A., Al-Sweasy, O.H. and Elazab, H.A. (2017) Preparation of Hydrogel Based on Acryl Amide and Investigation of Different Factors Affecting Rate and Amount of Absorbed Water. Agricultural Sciences, 8, 161170.

https://doi.org/10.4236/as.2017.82011

Received: November 26, 2016

Accepted: February 10, 2017

Published: February 13, 2017

Copyright $\odot 2017$ by authors and Scientific Research Publishing Inc. This work is licensed under the Creative Commons Attribution International License (CC BY 4.0).

http://creativecommons.org/licenses/by/4.0/

(c) (i) Open Access

\begin{abstract}
Hydrogel is considered as an important material in our world nowadays as it is used in many important and significant applications such as in tissue engineering and agriculture. There are hundreds of types of such materials, where most of them can be easily prepared. The main objective of this work is to prepare one of the hydrogel types which could be very useful in the agriculture of deserts where plants in dry places require water in order to grow up. There are many places around the world where raining occurs only once or twice a year. There are also places where it does not rain at all. Therefore, hydrogels are required in order to absorb water in large quantities either during raining or irrigation instead of escaping to underground and then eject them to the roots of plants over time as the plants require watering. In this research a hydrogel based on acryl amide, Poly 2-Acrylamide-2-Methyl-1-Propane Sulphonic Acid, (PAMPS) was prepared by using different percentages of a suitable cross-linking agent, Methylene-bis-Acrylamide. The cross-linker content is very important factor affects the rate and amount of absorbed water. The highest amount of absorbed water at $25^{\circ} \mathrm{C}$ was observed by using $0.6 \%$ cross-linking agent based on monomer mass. The temperature of absorbed water and its $\mathrm{pH}$ value are also essential factors that affect the rate and the amount of absorbed water and were investigated in this work. The highest amount of absorbed water was recorded at $\mathrm{pH}=12$ and at $60^{\circ} \mathrm{C}$. The amount and the rate of water absorbed by Sodium Polyacrylate Hydrogel were also investigated at $25^{\circ} \mathrm{C}$. The agriculture applications of hydrogel based on Sodium Polyacrylate were examined using Fenugreek seeds implanting.
\end{abstract}

\section{Keywords}

Hydrogel, Acryl Amide, Poly 2-Acrylamide-2-Methyl-1-Propane Sulphonic Acid, (PAMPS), Cross-Linking Agent, Sodium Polyacrylate Hydrogel 


\section{Introduction}

Hydrogels are very important class of thermo-setting polymers due to their ability of swallowing great amount of water up to hundred times the authentic weight of the arid polymer and hence they are very useful and could benefit the agriculture of deserts by absorbing large quantities of water during rain and then eject them to the roots of plants over relatively long time. Hydrogel, which is also known as super absorbent polymer, is a type of polymer whose structure is three dimensional and it is capable of swelling and absorbing large amounts of water. Such absorption of water depends on many factors such as type of the polymer, temperature, $\mathrm{pH}$ of water, and other factors such as the cross linking density [1] [2]. Hydrogels have many useful applications. These superabsorbent molecules are important in wound dressing, baby diapers, agriculture, and many other uses such as tissue engineering [1] [3]. The main characteristic of the hydrogel is the permeability and the ability of retaining water. Therefore, the hydrogel would accomplish an equilibrium swelling state [3]. The production of the first hydrogel polymer was in 1938 by the polymerization of both di-vinyl benzene and acrylic acid under high temperature in aquatic environment [4]. Selected types of hydrogel were employed in the biomedical field for contact lenses enhancement [5]. In 1960s, the USDA (United Stated Department of Agriculture) did some studies on hydrogels for the agriculture industry. This type of hydrogel had an absorption rate about 400 times its weight. However, it was unsuccessful in the market due to its expenditure and low strength [6]. Consequently, hydrogels brought about enormous transformation in the particular healthiness care manufacture in simply over a decade [7]. At the end of the year 1990, the world manufacture of hydrogel polymers exceeded a million ton. There are many companies that manufacture hydrogels, for example, Sanyo, Nalco, and some other manufacturers such as Hoechst, and Colon [8]. In 2004, hydrogel polymers were introduced in the Middle East by an Iranian company known as Rahab Resin Company [8]. The distribution of production of hydrogel polymers as introduced by EDANA (European Disposables and Nonwovens Association) [9] showed that the entire manufacture of hydrogel reached about million and a half tons in the year 2005. Afterwards, hydrogels have been used and enhanced in many applications such as toys, agriculture, and other uses. This field is now gaining attention essentially in food manufacture [3]. In the 1950s, the soluble polymeric soil products were introduced, but they failed in the field as they were soluble in water and thus had a short life time and they were not successfully applied to the soil for many reasons [10]. Many experiments have been carried out to develop these polymers so as not to destroy plants or soil. After further researches and experiments, hydrogels were discovered. Jellylike insoluble in water gels that absorb greater amounts of water than typical polymers and do not empty themselves easily even at higher pressure [10]. Hydrogels, as discussed before, have a great ability to absorb water up to 1.5 Liters per dry gram of hydrogels material. When Hydrogels are dry, they are in a crystalline glass form and once they contact water they turn into jelly-like materials 
that are soft. Hydrogels also allow the soil to breathe freely; benefitting from all elements and minerals it can indulge from air and soil [10]. Hydrogels also allow farmers to reduce the usage of fertilizers as they separate between soil particles allowing it to absorb fertilizers easily [11] [12] [13] [14] [15]. Many applications in agriculture have been invented and developed relying on hydrogels. One of the very important applications is "water reservoir" which is a system built beneath the soil allowing a good distribution of water and hydrogels are implanted through it. "Water reservoir" has been tested to be used in dry areas such as deserts. They succeeded in applying those avoiding lots of money to be spent and giving better quality of plant. Now it is used in many regions throughout the world. Water reservoir is one of hydrogels applications in agriculture. Water reservoirs are used with a specific strategy. When soil is watered, their roots are not that absorb water, hydrogels do until saturation. A very well know super absorbent has been developed recently by an Italian Scientist by using citric acid cross linked with a hydrogel cellulose [16].

\section{Experimental}

\subsection{Materials}

The monomer 2-Acrylamide-2-Methyl-1-Propane Sulphonic Acid, (AMPS) and the cross-linking agent, Methylene-bis-Acrylamide were obtained from Sigma Aldrich company as commercial grade while, the initiator, ammonium persulphate was purchased from Alfa Chemicals as commercial grade.

\subsection{Preparation of PAMPS Hydrogels}

The monomer (AMPS), $(5 \mathrm{~g})$ was added to about $12.5 \mathrm{ml}$ of distilled water in a conical flask. A specific amount of methylene-bis-acrylamide which acts as the cross linking agent was then added. The mixture was shaken well and inert nitrogen gas was then passed through the mixture for 2 minutes in order to remove oxygen and make an inert blanket. Then, quickly after passage of nitrogen gas, about $0.02 \mathrm{~g}$ of ammonium persulphate was added to the solution which acts as the initiator. The solution was then poured in a test tube and then covered with an appropriate cork. The test tube is then put in an oven at $60^{\circ} \mathrm{C}$ for about 2 - 3 hours. Then after that time hydrogel is obtained and cut into disks.

\subsection{Examination of Different Cross Linking Densities}

In the typical practical work, six different samples of PAMPS of different methylene-bis-acrylamide (cross linking agent) amounts were prepared. The used amounts by weight of the cross linking agent were $0.03,0.09,0.15,0.25,0.35$, and $0.55 \mathrm{~g}$. after preparing the different samples, a certain weight of the hydrogel is placed in a beaker and $200 \mathrm{ml}$ of water was added to each sample in order to determine the amount of water absorbed as time elapsed.

\subsection{Investigating the Effect of Water $\mathrm{pH}$}

Methylene-bis-acrylamide (0.15 g) cross linked PAMPS hydrogel was prepared 
and then three certain weights of this sample were taken, where each sample was placed in a beaker in which $200 \mathrm{ml}$ of water at $25^{\circ} \mathrm{C}$ was added. One of the hydrogels was left with the water neutral $(\mathrm{pH}=7)$. For the second hydrogel sample, the water to be absorbed was made acidic by adding some drops of hydrochloric acid (HCL) till the $\mathrm{pH}$ was adjusted to be 4 . Finally, for the third hydrogel sample, the water to be absorbed was made alkaline by adding small pieces of sodium hydroxide chips $(\mathrm{NaOH})$ till the $\mathrm{pH}$ was adjusted to be 12 .

\subsection{Examination of the Effect of Water Temperature}

Methylene-bis-acrylamide $(0.15 \mathrm{~g})$ cross linked PAMPS hydrogel was prepared and then three certain weights of this sample were taken, where each sample was placed in a beaker in which $200 \mathrm{ml}$ of water was added. One of the hydrogels was left with the water at room temperature $25^{\circ} \mathrm{C}$. For the second hydrogel sample, the water to be absorbed was heated to $40^{\circ} \mathrm{C}$ in a water bath maintained at $40^{\circ} \mathrm{C}$. Finally, for the third hydrogel sample, the water to be absorbed was heated to $60^{\circ} \mathrm{C}$ in a water bath maintained at $60^{\circ} \mathrm{C}$.

\subsection{Sodium Polyacrylate Hydrogel}

Sodium polyacrylate hydrogel can be obtained by extracting the super absorbent polymer found in a diaper. The diaper from which the sodium polyacrylate was extracted is Molfix diapers (Junior). Such diaper is made in Egypt by Hayat Egypt Hygienic Products (S.A.E) where the factory is located in sixth of October city. The sodium polyacrylate hydrogel obtained from this type of diaper is in the form of very fine white crystals.

\subsection{Sodium Polyacrylate Hydrogel Agricultural Test}

An experiment was carried out to apply this methodology of hydrogels in implanting and observe the results comparing it to the other regular farming method. Hydrogel crystals are put beneath the soil surface, a single layer of hydrogel beneath the soil is enough, and traditional farming methods are applied starting from watering the soil and applying enough sunlight to the plant.

\section{Results and Discussion}

\subsection{Effect of Cross-Linker Percent}

As shown in Figure 1, the mass of cross-linker is based on the mass of monomer which is $5 \mathrm{~g}$. Hence, $0.03 \mathrm{~g}$ of cross-linker is equivalent to $0.6 \%$ of monomer mass; $0.15 \mathrm{~g}$ of cross-linker is equivalent to $3 \%$ of monomer mass, and so on. In case of $0.03 \mathrm{~g}$ cross linking agent, the figure shows a very high and constant slope for the first 12 hours, while after 12 hours, the slope started to decrease and became unsteady. The volume of water absorbed per unit weight of the polymer could increase the polymer mass to two hundred times its original weight after 240 hours.

Similarly, In case of $0.09 \mathrm{~g}$ cross linking agent, the figure shows a high and constant slope for the first 7 hours, while after 7 hours; the slope started to decrease 


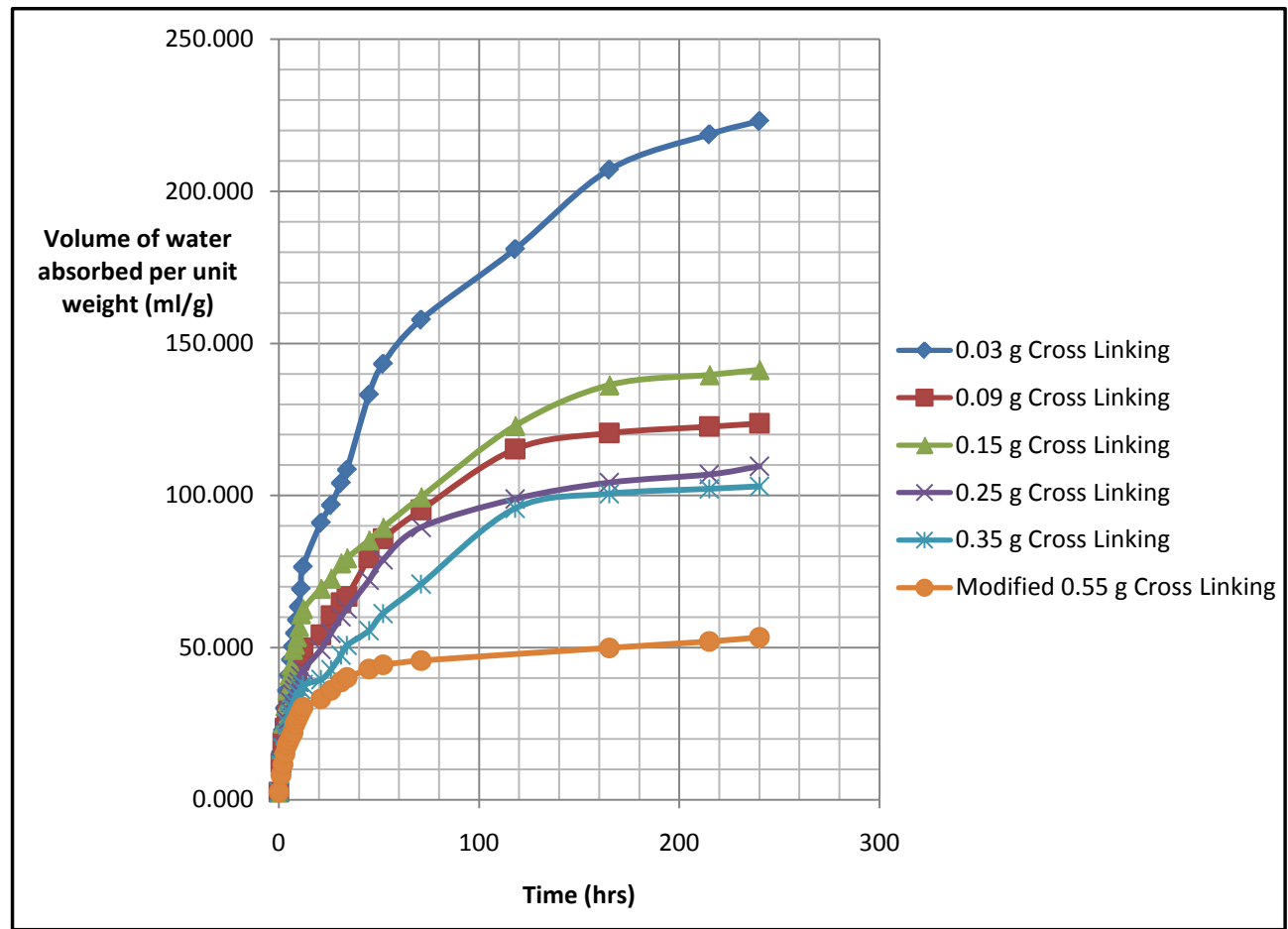

Figure 1. Relation between water absorbed by PAMPS hydrogel and time in case of different cross linking densities.

showing another constant slope from the hour 21 till 150 hours of the experiment. The volume of water absorbed per unit weight of the polymer could increase the polymer mass to one hundred and forty one times its original weight after 240 hours. While, In case of $0.15 \mathrm{~g}$ cross linking agent, the figure shows a high and constant slope for the first 6 hours, while after 6 hours; the slope started to decrease showing another constant but lower slope from the hour 52 till 118 hours of the experiment. The volume of water absorbed per unit weight of the polymer could increase the polymer mass to one hundred and twenty three times its original weight after 240 hours. But, In case of $0.25 \mathrm{~g}$ cross linking agent, the figure also shows a high and constant slope for the first 7 hours, while after 7 hours; the slope started to decrease showing a constant decrease throughout the experiment.

The volume of water absorbed per unit weight of the polymer could increase the polymer mass to one hundred and ten times its original weight after 240 hours. In case of $0.35 \mathrm{~g}$ cross linking agent, the figure also shows a high and constant slope for the first 5 hours, while after 5 hours; the slope started to decrease and became unsteady. The slope then became constant but lower from the time 52 hours till 118 hours, then decrease and became constant again till the end of the experiment. The volume of water absorbed per unit weight of the polymer could increase the polymer mass to one hundred and three times its original weight after 240 hours. Finally, in case of $0.55 \mathrm{~g}$ cross linking agent, the figure shows a high and constant slope for the first 4 hours, while after 4 hours; the slope then was still decreasing till reaching 71 hours after which the slope is fixed 
till the end of the experiment. The volume of water absorbed per unit weight of the polymer could increase the polymer mass to fifty three times its original weight after 240 hours.

Generally, the previous figure, showed the different curves of the different cross linking densities PAMPS hydrogels. For the same time intervals, the $0.03 \mathrm{~g}$ cross linked PAMPS hydrogel showed the highest volume of water absorbed per unit weight followed by the $0.09 \mathrm{~g}, 0.15 \mathrm{~g}, 0.25 \mathrm{~g}, 0.35 \mathrm{~g}$ and finally $0.55 \mathrm{~g}$ cross linked PAMPS hydrogel which was the least volume of water absorbed per unit weight.

Generally the amount of absorbed water decreases as the cross-linking density increase due to decrease of the rooms available to absorb water as illustrated in Table 1.

\subsection{Effect of $\mathrm{pH}$ of Water}

Figure 2 shows the different curves of the amount and the rate of the water absorbed of different PAMPS hydrogel samples. In case of different water $\mathrm{pH}$ values for the same time intervals the hydrogel in case of alkaline water shows the

Table 1. Comparison between volumes of water absorbed for different cross linking densities of PAMPS hydrogel after 240 hours.

\begin{tabular}{cc}
\hline Cross Linking Density & Volume of Water Absorbed per Net Weight of Polymer $(\mathrm{ml} / \mathrm{g})$ \\
\hline $\mathbf{0 . 0 3} \mathbf{g}$ & 223.112 \\
$\mathbf{0 . 0 9} \mathrm{g}$ & 141.296 \\
$\mathbf{0 . 1 5} \mathbf{g}$ & 123.706 \\
$\mathbf{0 . 2 5} \mathrm{g}$ & 109.60 \\
$\mathbf{0 . 3 5} \mathrm{g}$ & 102.98 \\
$\mathbf{0 . 5 5} \mathrm{g}$ & 53.40 \\
\hline
\end{tabular}

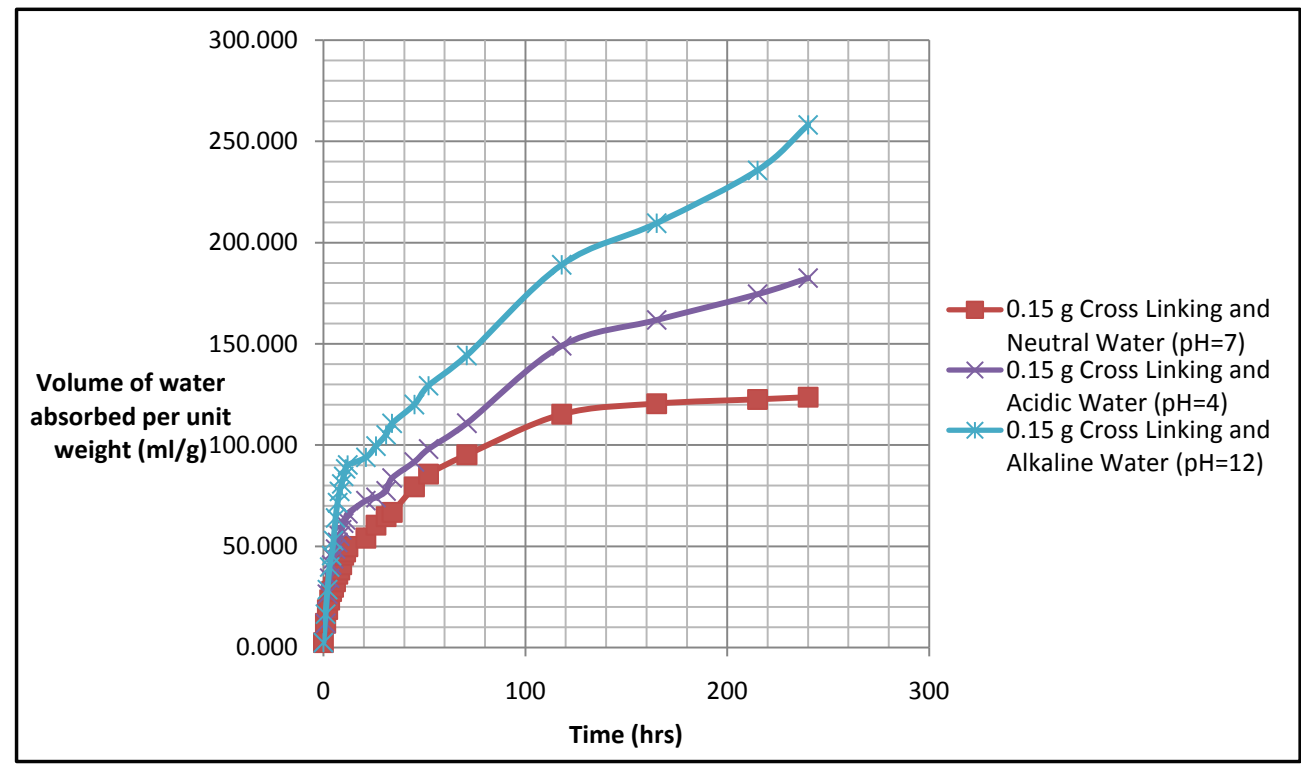

Figure 2. Relation between water absorbed by PAMPS hydrogel and time in case of different $\mathrm{pH}$. 
highest volume of water absorbed per unit weight of polymer (about six times that absorbed in neutral water, followed by the hydrogel in case of acidic water, and then in case of neutral water which shows the least volume of water absorbed per unit weight. This may be attributed to the acidic character of the polymer which contains a sulphonic acid group.

\subsection{Effect of Temperature of Water}

Figure 3 shows the different curves of the amounts of water absorbed by the different PAMPS hydrogel in case of different temperatures. For the same time intervals the hydrogel in case of water at temperature $60^{\circ} \mathrm{C}$ shows the highest volume of water absorbed per unit weight followed by the hydrogel in case of water at temperature $40^{\circ} \mathrm{C}$, and then in case of water at room temperature $25^{\circ} \mathrm{C}$ which that shows the least volume of water absorbed per unit weight which may be explained by the expansion of the rooms between cross-linking bonds by increasing the temperature.

\subsection{Investigating the Effect of Time on the Amount of Water Absorbed by Sodium Polyacrylate Hydrogel}

When using $0.2 \mathrm{~g}$ of this hydrogel in $200 \mathrm{ml}$ tap water at $25^{\circ} \mathrm{C}$ and observing the amount of water absorbed every 3 minutes, a relationship between the volume absorbed and time is drawn as shown in Figure 4.

The volume of water absorbed per unit weight of the sodium polyacrylate hydrogel increases with time until reaching 24 minutes. After this time the volume of water absorbed does not change with time showing that the hydrogel has reached saturation. The volume of water absorbed per unit weight of the polymer increases the polymer mass 205 times its original weight after 24 minutes only.

\subsection{Agriculture Application of Sodium Polyacrylate Hydrogel}

In the experiment that was carried out to apply this methodology of hydrogels in

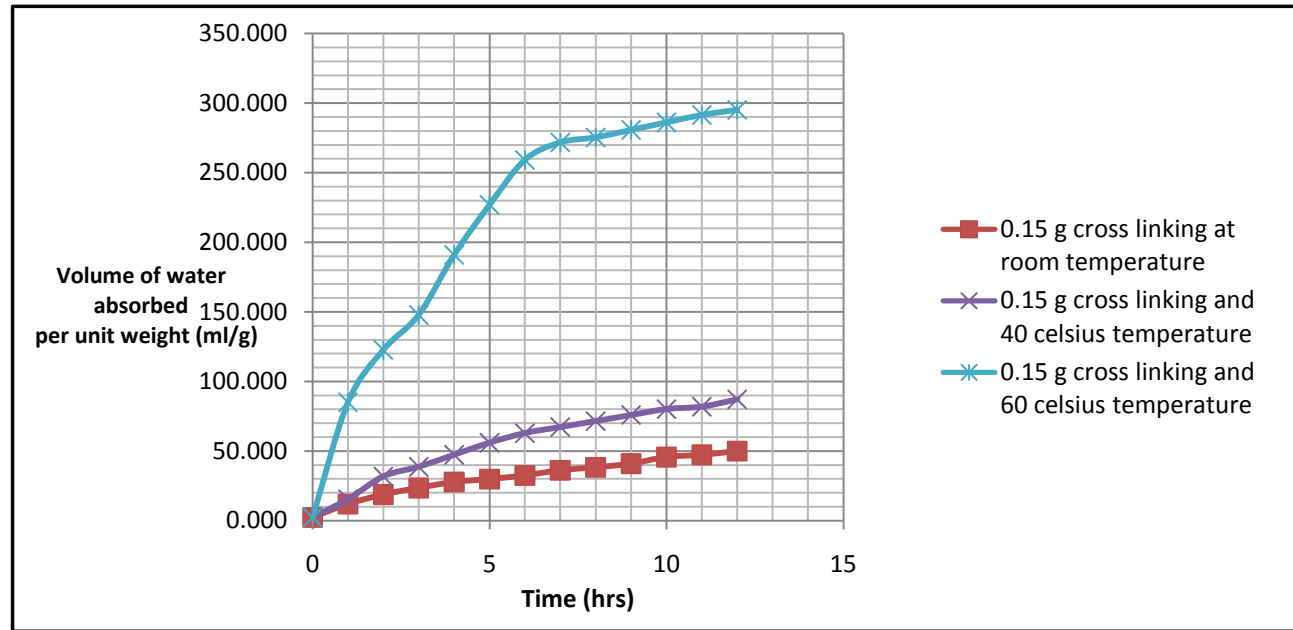

Figure 3. Relation between water absorbed by PAMP hydrogel and time in case of different water temperatures. 
implanting and observe the results comparing it to the other regular farming method. Hydrogel crystals are put beneath the soil surface, a single layer of hydrogel beneath the soil is enough, and traditional farming methods are applied starting from watering the soil and applying enough sunlight to the plant.

As shown in Figure 5, two plant pots are brought and equal amounts of soil is added to both pots, but adding the hydrogel crystals to one of the pots. Fenugreek seeds are put on the soil surface and then watered using a small cup of water. After three days of observations with regular but enough sunlight to both pots, observations will show that both plants started to grow; noticing that the pot with hydrogel crystals has grew a little more than the other one.

The two pots were left for a longer period to observe an effective change keeping both pots to enough sunlight. Seven days later, it was observed that the pot with hydrogel grew more and was healthy, while the other plant died and stopped growing.

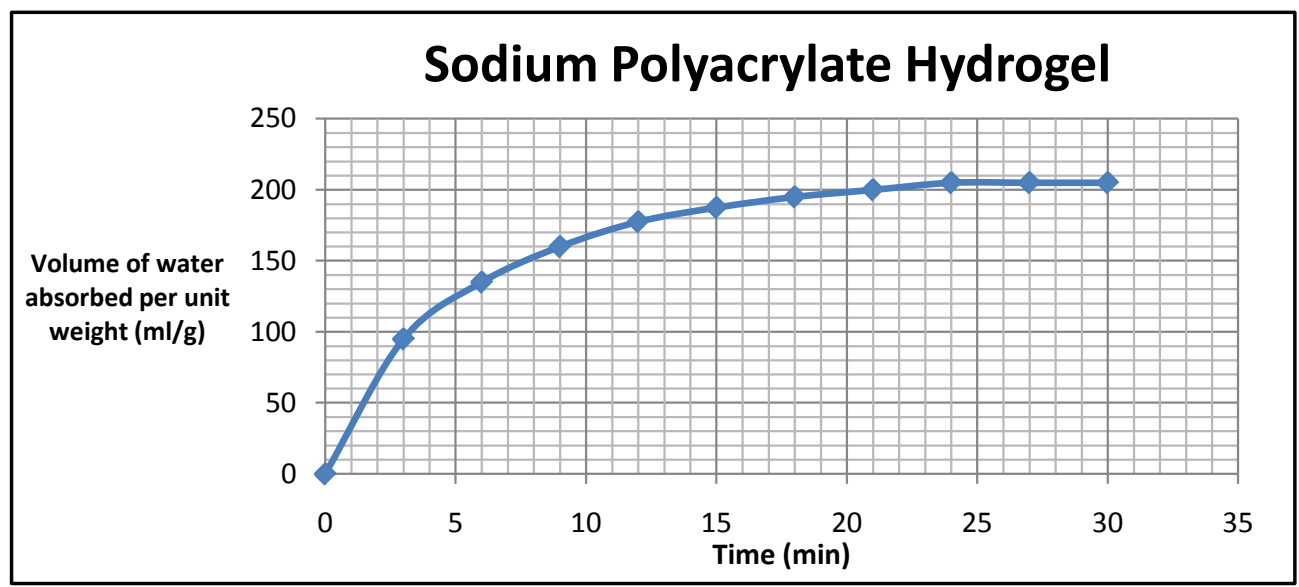

Figure 4. Relation between water absorbed by sodium polyacrylate hydrogel and time.

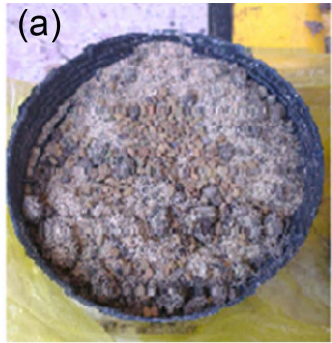

Day 0

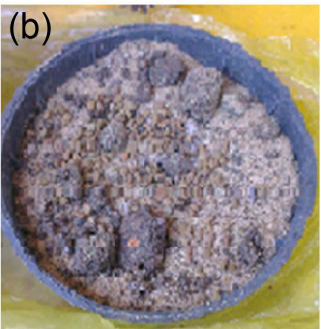

Day 0

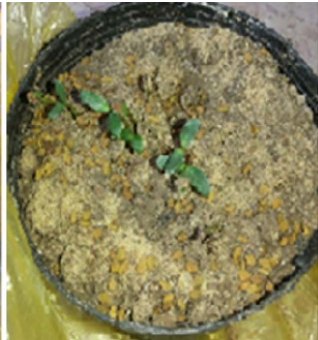

Day 3

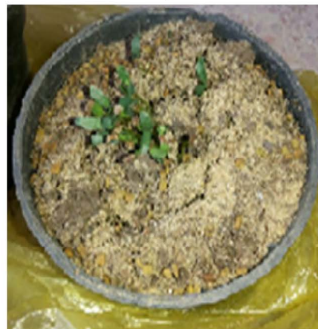

Day 3

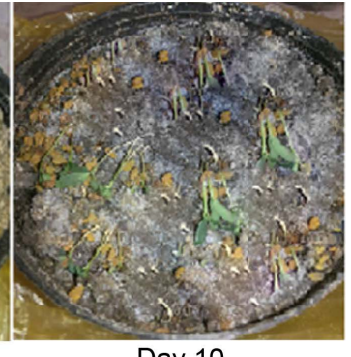

Day 10

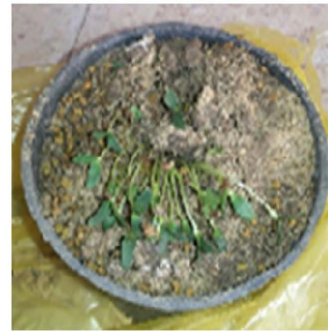

Day 10

Figure 5. Fenugreek seeds implanting (a) without hydrogel, (b) with using sodium polyacrylate hydrogel crystals. 


\section{Conclusion}

The relation between water absorbed by PAMPS hydrogel and time in case of different cross linking densities was investigated. For the same time intervals, the $0.03 \mathrm{~g}$ cross linked PAMPS hydrogel showed the highest volume of water absorbed per unit weight followed by the $0.09 \mathrm{~g}, 0.15 \mathrm{~g}, 0.25 \mathrm{~g}, 0.35 \mathrm{~g}$ and finally $0.55 \mathrm{~g}$ cross linked PAMPS hydrogel which was the least volume of water absorbed per unit weight. The study of the different PAMPS hydrogel in case of different water $\mathrm{pH}$ was also investigated. It was found that at the same time intervals the hydrogel in case of alkaline water shows the highest volume of water absorbed per unit weight followed by the hydrogel in case of acidic water, and then in case of neutral water which shows the least volume of water absorbed per unit weight. The study of the different PAMPS hydrogel in case of different temperatures was also investigated. For the same time intervals the hydrogel in case of water at temperature $60^{\circ} \mathrm{C}$ shows the highest volume of water absorbed per unit weight followed by the hydrogel in case of water at temperature $40^{\circ} \mathrm{C}$, and then in case of water at room temperature which shows the least volume of water absorbed per unit weight.

\section{References}

[1] Buchholz, F.L. and Graham, A.T. (1998) Modern Superabsorbent Polymer Technology. Wiley-VCH, New York.

[2] Brannon, L. and Horland, R.S. (1991) Absorbent Polymer Technology. Journal of Controlled Release, 17, 297-298.

[3] Hennink, W.E. and Nostrum, C.F. (2002) Novel Cross Linking Methods to Design Hydrogels. Advanced Drug Delivery Reviews, 54, 13-36. https://doi.org/10.1016/S0169-409X(01)00240-X

[4] Rosiak, J.M. and Yoshii, F. (1999) Hydrogels and Their Medical Applications. Nuclear Instrument and Methods in Physics Research Section B, 151, 56-64. https://doi.org/10.1016/S0168-583X(99)00118-4

[5] Dayal, U., Mehta, S.K., Choudhari, M.S. and Jain, R. (1999) Synthesis of Acrylic Superabsorbents. Journal of Macromolecular Science, Part C, 39, 507-525.

[6] Buchholz, F.L. and Peppas, N.A. (1994) Superabsorbent Polymers Science and Technology. ACS Symposium Series, 573, American Chemical Society, Washington DC, Ch 2, 7, 8, 9.

[7] Brannon, L. and Harland, R.S. (1990) Absorbent Polymer Technology. Elsevier, Amsterdam, Ch 1-4.

[8] Superabsorbent Hydrogels, Website of the Leading Iranian Manufacturer of Superabsorbent Polymers; Rahab Resin Co., Ltd.; 10 September 2007.

[9] Superabsorbents, Website of the European Disposables and Nonwovens Association (EDANA). www.edana.org, available in 28 May 2008.

[10] Ecofriend (2010) Belgian Scientist Uses Hydrogels to Turn Dirt into Gardens.

[11] Carpi, A. Analysis and Modelling to Technology Applications. ISBN: 978-953-307268-5

[12] Lugao, A.B. and Malmonge, S.M. (2001) Use of Radiation in the Production of Hydrogels. Nuclear Instruments and Methods in Physics Research Section B, 185, 3742. https://doi.org/10.1016/S0168-583X(01)00807-2 
[13] Yue, H., Liao, L., Li, X. and Cui, Y. (2009) Study on the Swelling, Shrinking and Bending Behavior of Electric Sensitive Poly(2-acrylamido-2-methylpropane sulfonic acid) Hydrogel, 115-117.

[14] Radwan, M. and Al-Swuasy, O. (2014) Graduation Project Thesis, Chemical Engineering Department, The British University in Egypt, El Sherouk.

[15] Jhurry, D. (1997) Food and Agricultural Research Council, Reduit, Mauritius 109, Agricultural Polymers, AMAS 1997, University of Mauritius, Réduit.

[16] Sannino, A. (2008) Application of Superabsorbent Hydrogels for the Optimization of Water Resources in Agriculture. Department of Innovation Engineering, University of Salento, Monteroni.

Submit or recommend next manuscript to SCIRP and we will provide best service for you:

Accepting pre-submission inquiries through Email, Facebook, LinkedIn, Twitter, etc. A wide selection of journals (inclusive of 9 subjects, more than 200 journals)

Providing 24-hour high-quality service

User-friendly online submission system

Fair and swift peer-review system

Efficient typesetting and proofreading procedure

Display of the result of downloads and visits, as well as the number of cited articles

Maximum dissemination of your research work

Submit your manuscript at: http://papersubmission.scirp.org/

Orcontact as@scirp.org 